\title{
BMJ Open Determinants of antenatal care utilisation in sub-Saharan Africa: a systematic review
}

\author{
Ijeoma Nkem Okedo-Alex, ${ }^{1,2}$ Ifeyinwa Chizoba Akamike, ${ }^{1,2}$ \\ Obumneme Benaiah Ezeanosike, ${ }^{3}$ Chigozie Jesse Uneke ${ }^{1}$
}

To cite: Okedo-Alex IN, Akamike IC, Ezeanosike OB, et al. Determinants of antenatal care utilisation in sub-Saharan Africa: a systematic review. BMJ Open 2019;9:e031890. doi:10.1136/ bmjopen-2019-031890

- Prepublication history and additional material for this paper are available online. To view these files, please visit the journal online (http://dx.doi. org/10.1136/bmjopen-2019031890).

Received 23 May 2019

Revised 13 September 2019

Accepted 13 September 2019

Check for updates

(C) Author(s) (or their employer(s)) 2019. Re-use permitted under CC BY-NC. No commercial re-use. See rights and permissions. Published by BMJ.

${ }^{1}$ African Institute for Health Policy and Health Systems, Ebonyi State University, Abakaliki, Ebonyi, Nigeria ${ }^{2}$ Department of Community Medicine, Alex Ekwueme Federal University Teaching Hospital, Abakaliki, Ebonyi, Nigeria

${ }^{3}$ Department of Paediatrics, Alex Ekwueme Federal University Teaching Hospital, Abakaliki, Ebonyi, Nigeria

Correspondence to Dr ljeoma Nkem Okedo-Alex; ijeomaninadr@gmail.com

\section{ABSTRACT}

Objectives To identify the determinants of antenatal care (ANC) utilisation in sub-Saharan Africa.

Design Systematic review.

Data sources Databases searched were PubMed, OVID, EMBASE, CINAHL and Web of Science.

Eligibility criteria Primary studies reporting on determinants of ANC utilisation following multivariate analysis, conducted in sub-Saharan Africa and published in English language between 2008 and 2018.

Data extraction and synthesis $A$ data extraction form was used to extract the following information: name of first author, year of publication, study location, study design, study subjects, sample size and determinants. The Preferred Reporting Items for Systematic Reviews and Meta-Analyses checklist for reporting a systematic review or meta-analysis protocol was used to guide the screening and eligibility of the studies. The Quality Assessment Tool for Observational Cohort and Cross-Sectional Studies was used to assess the quality of the studies while the Andersen framework was used to report findings. Results 74 studies that met the inclusion criteria were fully assessed. Most studies identified socioeconomic status, urban residence, older/increasing age, low parity, being educated and having an educated partner, being employed, being married and Christian religion as predictors of ANC attendance and timeliness. Awareness of danger signs, timing and adequate number of antenatal visits, exposure to mass media and good attitude towards ANC utilisation made attendance and initiation of ANC in first trimester more likely. Having an unplanned pregnancy, previous pregnancy complications, poor autonomy, lack of husband's support, increased distance to health facility, not having health insurance and high cost of services negatively impacted the overall uptake, timing and frequency of antenatal visits.

Conclusion A variety of predisposing, enabling and need factors affect ANC utilisation in sub-Saharan Africa. Intersectoral collaboration to promote female education and empowerment, improve geographical access and strengthened implementation of ANC policies with active community participation are recommended.

\section{INTRODUCTION}

Globally, pregnancy and childbirth are significant events for women and their families even though they represent a period of

\section{Strengths and limitations of this study}

- This study involved a large number of studies that covered a wide and geographically important subregion of Africa.

- This study accessed several databases and used recent publications ( $\leq 10$ years old).

- This review provides evidence on the role of social determinants of health in antenatal care (ANC) utilisation and the importance of intersectoral collaboration in improving ANC utilisation.

- This review excluded publications in French language which may limit the representativeness and generalisability of the findings to some settings.

heightened vulnerability for both women and their unborn babies. ${ }^{1}$ Every day, preventable causes related to pregnancy and childbirth lead to the deaths of over 800 women with $99 \%$ of these maternal deaths occurring in low and lower middle-income countries. Although by 2015, maternal mortality had decreased by over 40\% from the 1990 levels, maternal mortality levels have continued to remain unacceptably high in sub-Saharan Africa (SSA) ${ }^{23}$ Inadequate access to quality antenatal care (ANC) contributes significantly to these preventable maternal deaths. ${ }^{4}$

As part of reproductive healthcare, ANC presents a unique and lifesaving opportunity for health promotion, disease prevention, early diagnosis and treatment of illnesses in pregnancy using evidence-based practices. ${ }^{5}$ To ensure optimum care, the WHO previously recommended that every pregnant woman should have a minimum of four ANC visits throughout the pregnancy with the first visit occurring in the first trimester of pregnancy. ${ }^{67}$ However in 2016, WHO revised its recommended minimum number of ANC visits from four to eight contacts following recent evidence that increased number of contacts between a pregnant woman and a skilled health provider reduced perinatal 
mortality and improved women's experience of care. Early ANC initiation in the first trimester of pregnancy and receiving the required services is emphasised in the revised guideline. ${ }^{5}$ In spite of this, global reports in 2017 showed that only three in five women attended at least four antenatal visits. In regions with the highest rates of maternal mortality, such as SSA, only $52 \%$ of women received at least four ANC visits. ${ }^{8}$

ANC promotes the health of pregnant women and has been found to reduce the risk of adverse pregnancy outcomes, perinatal and infant mortality and morbidity. ${ }^{9-12}$ It also encourages skilled birth attendance for delivery and postnatal care as women who attend ANC are more likely to use these services than the non-attenders. ${ }^{13-18}$ Studies have used a variety of indicators to assess ANC use. This includes at least one visit, at least four visits, trimester timing of ANC visits, services received during ANC visits and care provider type visited, however the quantity of contacts remains commonly used. ${ }^{19}$ Recently, indicators to enable the progressive realisation of maternal health targets have been proposed especially for low and middle-income country contexts like countries in SSA. ${ }^{19}$ The Andersen framework is a behavioural model that describes the social, individual and health system determinants affecting access to healthcare services. Several studies have employed this model in identifying the factors affecting ANC utilisation. ${ }^{20-27}$

Various studies have assessed factors affecting ANC utilisation in SSA countries, ${ }^{28-35}$ but none has systematically summarised such studies in SSA. A review conducted over 10 years ago examined factors affecting the use of ANC in low and middle-income countries, however this review only contained seven studies from Africa and did not include recently published studies from SSA. ${ }^{36}$ The aim of this review was to systematically identify the factors associated with the utilisation of ANC in SSA.

\section{METHODS}

The Preferred Reporting Items for Systematic Reviews and Meta-Analyses checklist for reporting a systematic review or meta-analysis protocol ${ }^{37}$ was used in screening studies for eligibility (see online supplementary file 1 ).

\section{Search strategy}

A systematic review of published quantitative literature was conducted between October 2018 and April 2019 to capture studies published in the last 10 years (2008-2018). The databases searched were PubMed, OVID, EMBASE, CINAHL and Web of Science. Other databases searched were Google Scholar and African Journal Online. The search terms used include: antenatal, prenatal, maternal health, maternal care, maternal health services, utilisation, factors, determinants, predictors, Africa. The search strategy and results are provided in online supplementary file 2 .

\section{Inclusion criteria}

Studies were eligible for inclusion if they were quantitative (primary or secondary data used) reporting on factors associated with ANC utilisation following multivariate analysis, conducted in SSA and published between 2008 and 2018. ANC utilisation in this review refers to attendance of at least one and at least four ANC visits and booking visit within the first trimester of pregnancy. Various study designs (longitudinal, cohort, case-control, cross-sectional and experimental) were eligible for inclusion if they assessed the predictors of ANC utilisation.

\section{Exclusion criteria}

This review excluded articles and studies published before 2008 and written in any language other than English. Studies that used measures other than the WHO recommendation for ANC were excluded. Review articles, case reports, case studies and simple descriptive studies without regression analyses were excluded. At the level of titles, titles that did not address ANC and maternal health/health services utilisation were excluded. At the abstracts stage, studies that did not report factors associated with ANC and qualitative studies were excluded. Full-text quantitative studies that did not report on the determinants of ANC utilisation after multivariable regression analysis such as studies that assessed the predictors of utilisation skilled birth attendance and postnatal care were excluded. Full-text publications that did not employ the WHO definitions for ANC and qualitative were also excluded

\section{Data extraction}

A data extraction form was developed and reviewed by all reviewers. Screening of titles and abstracts and the full texts was carried out independently by two of the review authors (INOA and ICA). Any disagreements were resolved through discussion and consensus between the two review authors or with the help of the third author (OBE). Mendeley reference manager was used to keep track of references. Data were extracted for each paper using standardised forms with the following domains: the name of first author and year of publication, study location and setting, study design, study subjects and sample size and factors/determinants. Figure 1 shows the article selection and inclusion process.

\section{Quality appraisal}

Quality assessment of the studies included in this review was carried out by the main reviewer in consultation with the other authors. The Quality Assessment Tool for Observational Cohort and Cross-Sectional Studies was used to assess the quality of the studies. This quality assessment tool has been used in other systematic reviews ${ }^{38}{ }^{39}$ (see online supplementary file 3). The tool consists of 14 questions assessing different aspects of a study including but not limited to definition of objectives, study population, sampling strategy, sample size and statistical analyses. To appraise a study, each question is scored as Yes (1) or No $(0)$, and others $(\mathrm{CD}$, cannot determine; NA, not applicable and NR, not reported). All the studies included in this review were assessed for quality using the appropriate 


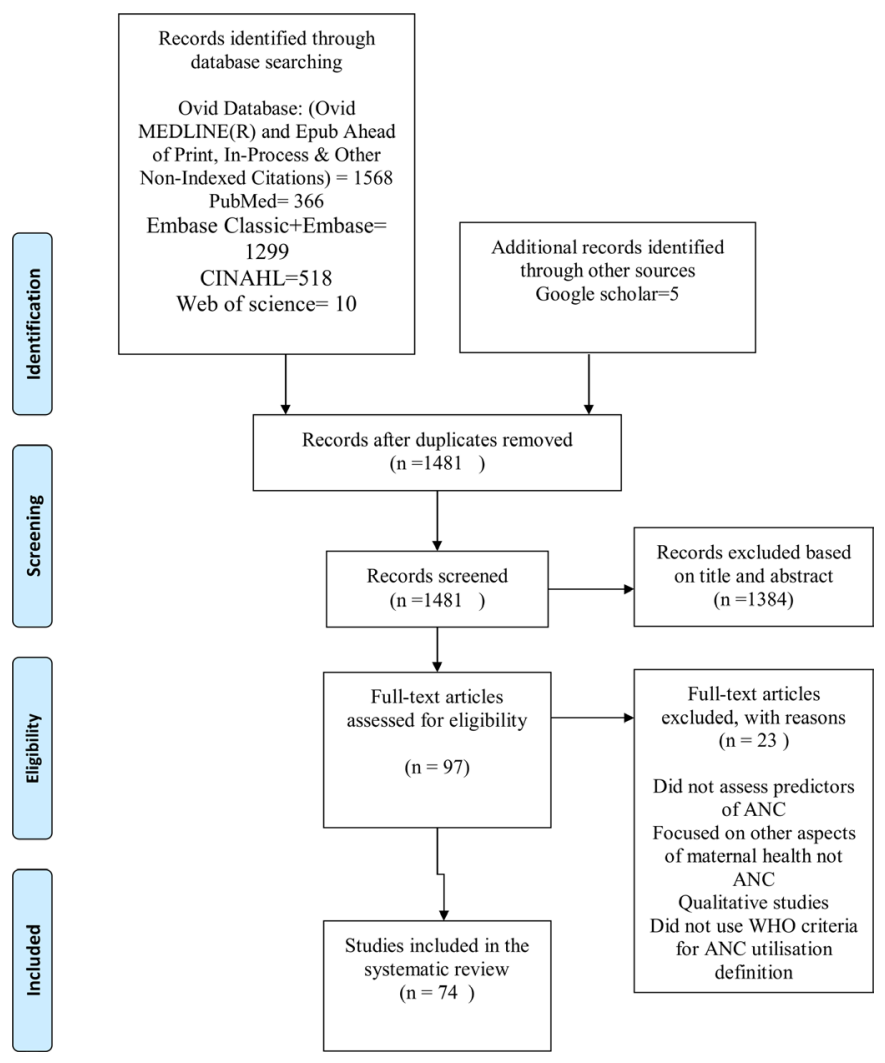

Figure 1 Selection and inclusion process for articles included in the review. ANC, antenatal care.

criteria based on study design. Elements of the criteria which did not apply to a particular study were marked as not applicable.

All the studies fulfilled the quality criteria except for six studies $^{940-44}$ that did not report on sample size.

\section{Patient and public involvement}

It was not appropriate or possible to involve patients or the public in this work

\section{RESULTS}

\section{Study selection}

The search yielded 3248 studies. The initial search identified a total of 3243 articles from the main databases and five articles from Google Scholar. After removal of duplicates, 1481 articles remained. Using title and abstracts, we first screened the identified articles and excluded 1384 articles based on the agreed inclusion criteria with the other three authors. The studies were excluded because they were irrelevant to the study, conducted outside SSA and were purely descriptive. A total of 97 full-text studies were assessed for eligibility and 23 articles were further excluded after reading the full text because they did not assess predictors of ANC, did not use the WHO definitions for ANC, were focused on other aspects of maternal health not specific to ANC and were qualitative studies. The four reviewers agreed on the inclusion of 74 studies in the final review.
The 74 studies included were from 23 SSA countries. East Africa had the highest number of studies included in this review. Countries with the most studies were Ethiopia (24), Nigeria (15), Kenya (5) and Ghana (5). Most studies were cross-sectional surveys and secondary data analyses (table 1). Table 2 contains the determinants of ANC utilisation classified as overall uptake of ANC (at least one $\mathrm{ANC}$ visit), frequency (at least four ANG visits) and initiation of ANC in first trimester. Table 3 contains the summary of the determinants of ANC utilisation by regions in Africa. The characteristics and summary of findings of the articles included in the review are presented in online supplementary file 4 tables 1 and 2. The summary measure used by various studies was mostly the OR.

The study findings were presented using the Andersen framework for the utilisation of health services. ${ }^{45}$ The Andersen framework is a health behaviour model used to assess the factors affecting health services utilisation. The model proposes three main determinants that influence the use of health services, including predisposing, enabling and need factors. These represent the preillness sociocultural characteristics, access-related factors and immediate cause/problems that generate a need for the use of health services, respectively. The predisposing factors include age, gender, marital status, family size, social status, education and race; enabling factors include family income, health insurance, distance, social relationships, service availability, and health facility characteristics (waiting time, availability of health providers) and need factors include symptoms or perceived illness. Under each main category (according to the Andersen framework), each determinant of ANG utilisation was presented with studies on its effect on overall uptake of ANC (at least one ANG visit), frequency (at least four ANC visits) and initiation of ANC in first trimester highlighted as applicable.

\section{Predisposing factors}

Maternal age

\section{Overall uptake of ANC (at least one ANC visit)}

Seven studies reported the effect of age on at least one ANC visit. Four of the studies showed that older/ increasing age was a predictor of ANC utilisation. ${ }^{46-49}$ Two of the studies conducted in Ethiopia found that younger age at first pregnancy was a predictor of ANC use as women aged less than or equal to 20 years at the time of first pregnancy were nearly three times more likely to use ANC services than whose age at first pregnancy was more than 20 years. $^{5051}$ Also, in one of the studies, Nigerian women aged less than 20 years were more likely to use ANC than their older counterparts ${ }^{23}$ (table 2).

\section{Frequency of ANC (at least four ANC visits)}

Nine studies found that maternal age significantly influenced the frequency of ANC visits. Eight of the studies found that older women were more likely to have at least four ANC visits compared with their younger counterparts. ${ }^{3034434952-55}$ One of the studies found that increasing 
Table 1 Summary of articles included in the review by regions

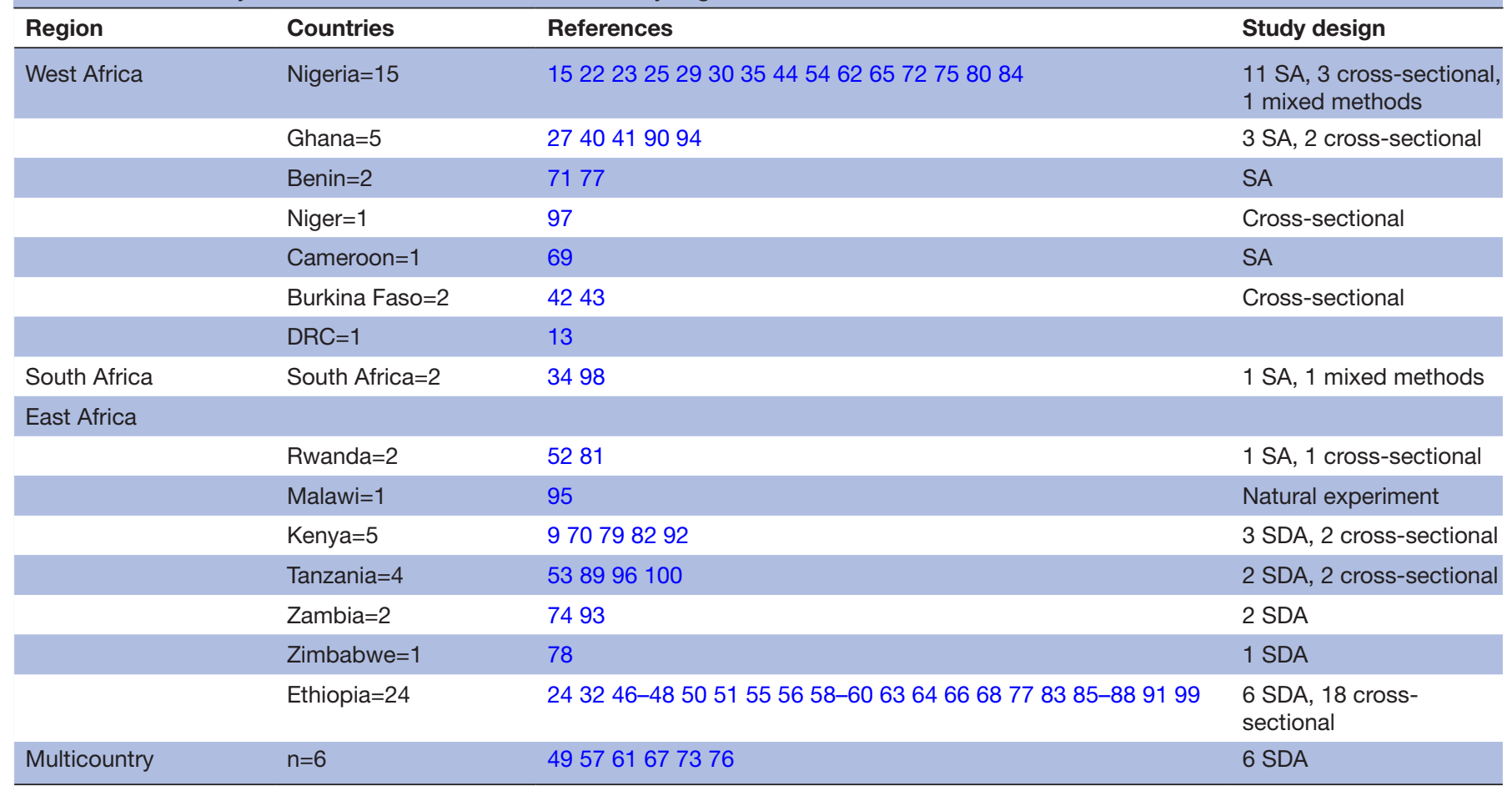

DRC, Democratic Republic of the Congo; SA, Secondary Data Analysis.

maternal age was associated with less than four ANC visits in Ethiopia ${ }^{33}$ (table 2).

Timing of first antenatal visit (gestational age $<12$ weeks)

Younger maternal age was a predictor of early ANC initiation in two of the studies ${ }^{5657}$ (table 2).

\section{Maternal education}

\section{Overall uptake of ANC (at least one ANC visit)}

In 19 studies, the relationship between maternal education and overall uptake of ANC was reported. The lack of formal education and lower educational levels were predictors of poor ANC use among women in these studies in 19 of the studies. $925464749-5153$ 58-68 However, one of the studies found that more educated women were less likely to use ANC from skilled medical providers ${ }^{23}$ (table 2).

\section{Frequency of ANC (at least four ANC visits)}

In 14 studies, maternal education was a predictor of frequency of ANC. In all the studies, the odds of attending at least four ANC visits was more in women who had higher educational levels $152425272930495354646769-71$ (table 2).

\section{Timing of first antenatal visit (gestational age $<12$ weeks)}

Six studies documented the relationship between maternal education and timing of initiating ANC. Five studies found that educated women were likely to book early for ANC. ${ }^{2456577072}$ Only one of the studies found that more educated women were less likely to use ANC from skilled medical providers ${ }^{23}$ (table 2).

\section{Husband/partner's education}

Overall uptake of ANC (at least one ANC visit)

Only one study conducted in Ethiopia found that the higher the educational status of the husbands, the more likely the woman will attend at least one ANC visit ${ }^{63}$ (table 2).

\section{Frequency of ANC (at least four ANC visits)}

Six studies reported on the influence of husband/partner's education on ANC use. Women whose husbands/ partners had some education were more likely to access ANC services than those with less educated husbands/ partners $^{22} 3041637374$ (table 2).

\section{Maternal occupation/employment status}

Overall uptake of ANC (at least one ANC visit)

Seven studies documented the impact of occupation/ employment status on uptake of ANC. In six of the studies, women who were employed and those who had a working status were found to be more likely to use ANC than the unemployed/not working. ${ }^{474862677576}$ Women who were farmers were more likely to use ANC in one of the studies $^{59}$ (table 2).

Frequency of ANC (at least four ANC visits)

Women who were employed were more likely to use ANC up to four times compared with their unemployed 
Table 2 Determinants of ANC uptake, frequency and timing

\begin{tabular}{|c|c|c|c|c|}
\hline Factor & Determinants & At least one ANC visit & At least four ANC visits & $\begin{array}{l}\text { Initiation of ANC in } \\
\text { first trimester }\end{array}$ \\
\hline \multicolumn{5}{|c|}{$\begin{array}{l}\text { Predisposing } \\
\text { factors }\end{array}$} \\
\hline & Maternal age & $2346-51$ & $303334434952-55$ & 5657 \\
\hline & Maternal education & $92325464749-515358-68$ & .1524252729304953546467 69-71 & 232456577072 \\
\hline & $\begin{array}{l}\text { Maternal occupation/ } \\
\text { employment status }\end{array}$ & 47485962677576 & $293033737477)$ & 335776 \\
\hline & Husband/partner's occupation & 68 & NA & NA \\
\hline & Husband/partner's education & 63 & 223041637374 & NA \\
\hline & Maternal religion & 487578 & 27546677 & 57 \\
\hline & Marital status and family type & 637980 & 427079 & 538182 \\
\hline & Parity/family and household size & 46474951606183 & 153040427077 & 57677881828485 \\
\hline & Ethnicity and cultural Influence & 616675 & 75 & NA \\
\hline & Residence/geographical location & 153335596264667378809091 & 44464849516380 & 33727892 \\
\hline \multicolumn{5}{|c|}{$\begin{array}{l}\text { Enabling } \\
\text { factors }\end{array}$} \\
\hline & $\begin{array}{l}\text { Household wealth/socioeconomic } \\
\text { status }\end{array}$ & $51606365-67718088$ & $152527293032415464697789-91$ & 5770 \\
\hline & Distance from health facilities & 9464861688693 & 345354 & 33727892 \\
\hline & $\begin{array}{l}\text { Health insurance/user-fee } \\
\text { exemption }\end{array}$ & 9495 & 415490 & 728196 \\
\hline & $\begin{array}{l}\text { Involvement in decision-making/ } \\
\text { autonomy }\end{array}$ & NA & 29307387 & 72 \\
\hline & $\begin{array}{l}\text { Husband/partner's approval and } \\
\text { support }\end{array}$ & 46505897 & 5298 & NA \\
\hline \multicolumn{5}{|c|}{ Need factors } \\
\hline & Knowledge/exposure to media & 4858758386 & 2230546477 & 7287 \\
\hline & $\begin{array}{l}\text { Attitude and perception towards } \\
\text { ANC }\end{array}$ & 46 & $(32$ & 5687 \\
\hline & $\begin{array}{l}\text { Pregnancy wantedness and } \\
\text { planning }\end{array}$ & 4647505558718385100 & 1353788198100 & 81 \\
\hline & $\begin{array}{l}\text { Current/previous pregnancy and } \\
\text { health experiences }\end{array}$ & 505589 & 87 & 5684 \\
\hline & Quality/content of services & 97 & 53608193 & NA \\
\hline
\end{tabular}

ANC, antenatal care; NA, not applicable.

counterparts in six of the studies. ${ }^{29} 30737477$ In another study, there was a higher odds of inadequacy in ANC visits among women who engaged in sales/business, agriculture, skilled manual and other jobs when compared with women who currently do not work ${ }^{33}$ (table 2 ).

Timing of first antenatal visit (gestational age $<12$ weeks)

Unemployed women were less likely to initiate ANC early in pregnancy in one study. ${ }^{57}$ In another study carried out in Ethiopia, women who were engaged in agricultural occupation were more likely to have delayed initiation of ANC. ${ }^{33}$ In Rwandan communities with higher employment rate among men, women were more likely to have received care early in the pregnancy ${ }^{76}$ (table 2 ).
Husband/partner's occupation

Overall uptake of ANC (at least one ANC visit)

One of the studies found that women whose husbands were engaged in non-farming occupations were more likely to use ANC services ${ }^{68}$ (table 2).

Maternal religion

Overall uptake of ANC (at least one ANC visit)

Two studies found that Christian women were more likely to use ANC services compared with non-Christians (traditional African religion and Muslims). ${ }^{7578}$ In another study, orthodox Christians used ANC more than the Protestants and Catholics group. ${ }^{48}$

Frequency of ANC (at least four ANC visits)

In two studies, Christians were more likely to use ANC services compared with non-Christians. ${ }^{54} 77$ Women who had no religion were less likely to attend ANC in two studies $^{2766}$ (table 2). 


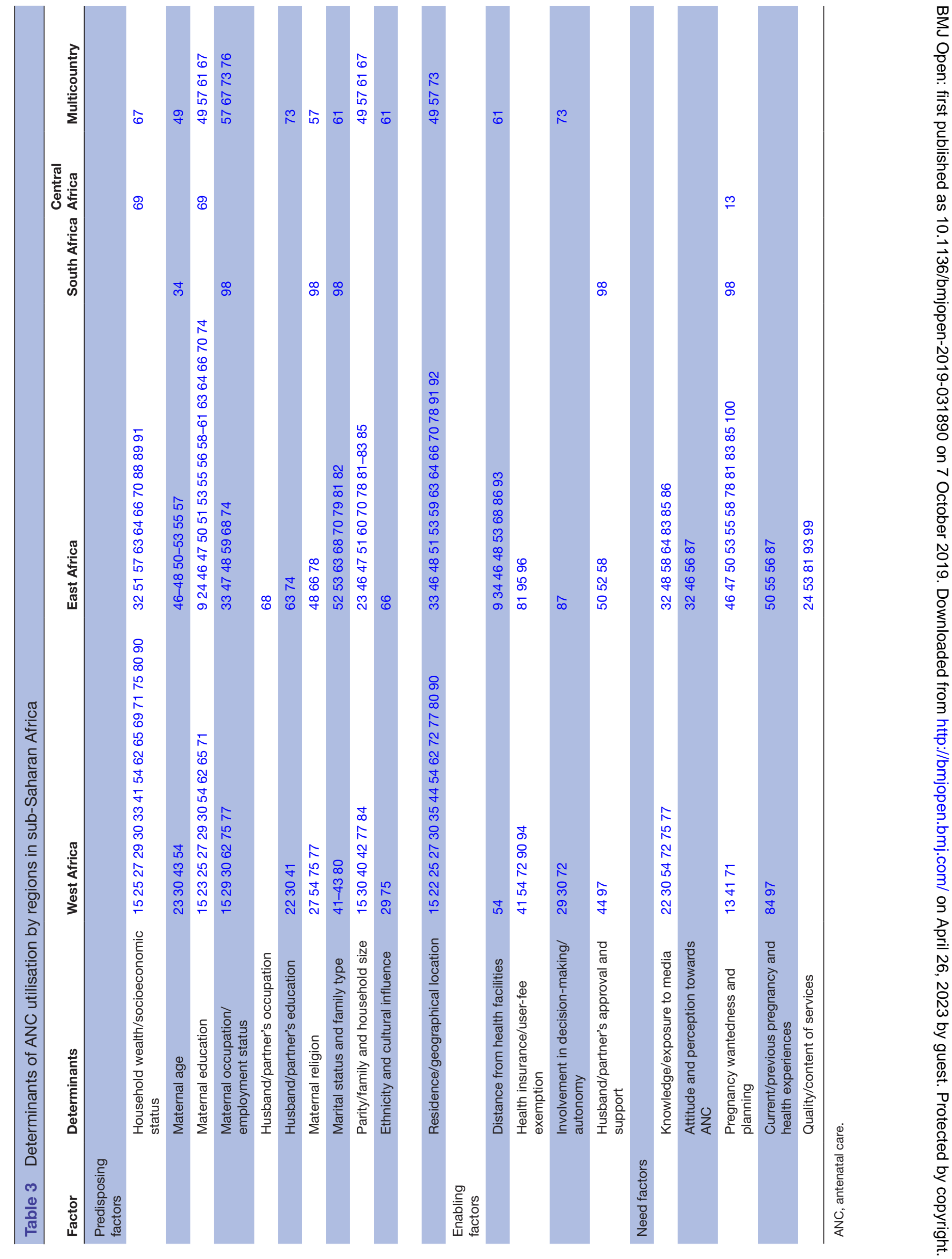


Timing of first antenatal visit (gestational age $<12$ weeks)

In one of the studies, women who were Muslims and traditionalists were less likely to initiate ANC in the first trimester $^{57}$ (table 2).

\section{Marital status and family type}

\section{Overall uptake of ANC (at least one ANC visit)}

Three of the studies assessed the effect of marital status on using ANC once in the course of pregnancy. These studies showed that married women were more likely to use ANC than the never married/currently unmarried. ${ }^{79} 80$ One of the studies employed a composite index (adequate ANC) comprising at least one, four ANC visits, ANC by skilled professional and number of services received. ${ }^{79}$ In another of the studies, never and formerly married women were more likely to use skilled ANC attendants ${ }^{63}$ (table 2).

\section{Frequency of ANC (at least four ANC visits)}

Three studies found that married women were more likely to make at least four ANC contacts than the unmarried during pregnancy ${ }^{42} 70$ (table 2).

\section{Timing of first antenatal visit (gestational age $<12$ weeks)}

In three studies, early ANC initiation was significantly associated with being married than being unmarried ${ }^{5381} 82$ (table 2).

\section{Parity/birth order and household size}

\section{Overall uptake of ANC (at least one ANC visit)}

Five studies found that women with high parity or large household sizes were less likely to attend at least one ANC visit. ${ }^{464796061}$ Women whose pregnancy was for the first time were more likely to use ANC services at least once during their pregnancy. ${ }^{51}$ In one other study, mothers with high parity were more likely to use ANC than those with low parity ${ }^{83}$ (table 2).

\section{Frequency of ANC (at least four ANC visits)}

In six of the studies, women with high parity or large household sizes had significant reduction in attainment of at least four ANC contacts in the course of pregnancy $^{15} 3040427077$ (table 2).

\section{Timing of first antenatal visit (gestational age $<12$ weeks)}

Five studies reported that low parity/null parity was a predictor of early booking while having many children led to delayed ANC initiation. ${ }^{576781828485}$ However, one of the studies showed that women who had given birth at least once were less likely to seek prenatal care in the first trimester $^{78}$ (table 2).

\section{Ethnicity}

\section{Overall uptake of ANC (at least one ANC visit)}

Three studies showed that within-country ethnic differences influenced attending at least one ANC visit in different countries ${ }^{616675}$ (table 2).
Frequency of ANC (at least four ANC visits)

One study identified within-country ethnic differences as a predictor of attending at least four ANC visits ${ }^{75}$ (table 2).

Knowledge of pregnancy/exposure to media

Overall uptake of ANC (at least one ANC visit)

In two studies, awareness of danger signs of pregnancy, timing and recommended number of ANC visits was a predictor of at least one ANC. ${ }^{583}$ Exposure to mass media has also increased the odds of attending at least one ANC visit $^{48587586}$ (table 2).

\section{Frequency of ANC (at least four ANC visits)}

Five of the studies showed that women exposed to mass media were more likely to use ANC services and promptly compared with those who were not ${ }^{22} 30546477$ (table 2).

\section{Timing of first antenatal visit (gestational age $<12$ weeks)}

A study conducted in Nigeria found that women who had been exposed to three media channels (radio, television and newspaper/magazine) were more likely to initiate ANC in the first trimester compared with those who were less exposed to the media. ${ }^{72}$ Another study showed that women who lacked information on correct time of booking were more likely to book late for $\mathrm{ANC}^{87}$ (table 2).

\section{Attitude and perception towards ANC}

\section{Overall uptake of ANC (at least one ANC visit)}

Women who considered pregnancy a risky event were more likely to use ANC than those who considered it risk free $^{46}$ (table 2).

\section{Frequency of ANC (at least four ANC visits)}

Women who had a good attitude towards maternal health were twice more likely to attend ANC compared with those with a poor attitude ${ }^{32}$ (table 2 ).

\section{Timing of first antenatal visit (gestational age $<12$ weeks)}

Two studies documented that women who perceived that ANC should be initiated in the first trimester were more likely to book early for ANC than those who perceived that ANC should commence in the second and third trimesters $^{5687}$ (table 2).

\section{Enabling factors}

Household wealth/socioeconomic status

Overall uptake of ANC (at least one ANC visit)

Nine studies showed high socioeconomic level positively influenced attendance of at least one ANC visit. $^{51} 606365-67718088$

\section{Frequency of ANC (at least four ANC visits)}

In 14 studies, women of high socioeconomic status (SES) attended at least four ANC visits more than those in the lowersocioeconomic/wealth strata ${ }^{152527293032415464697789-91}$ (table 2).

Timing of first antenatal visit (gestational age $<12$ weeks)

Lower wealth/poor SES was associated with late initiation of ANC in two studies ${ }^{57} 70$ (table 2). 
Place of residence/geographical location

Overall uptake of ANC (at least one ANC visit)

Eight studies reported the role of place of residence (urban/rural) on attendance to at least one ANC clinic. In all the studies, rural dwellers were reported to be less likely to attend at least one ANC visit. ${ }^{15} 33355964739091$ Living in communities where a government health facility was situated increased the odds of attending at least one ANC visit. ${ }^{78}$ Three studies reported increased likelihood of attending at least one ANC visit based on residence in specified geographical regions/locations within the countries where the studies were conducted ${ }^{626680}$ (table 2).

\section{Frequency of ANC (at least four ANC visits)}

In six of the studies, residing in the rural area made attending at least four ANC visits more likely than residing in the urban area. ${ }^{464849516380}$ One study showed that women residing in communities with a government health facility providing ANC services were more likely to have four ANC visits ${ }^{44}$ (table 2).

In eight studies, residing in a particular geographic region increased the likelihood of achieving at least four ANC visits during pregnancy. 2225273044535480 This varied by the different regional and zonal categories within each country (table 2 ).

\section{Timing of first antenatal visit (gestational age $<12$ weeks)}

Rural dwellers were more likely to present late for ANC (in second and third trimesters) in four of the studies included in this review ${ }^{33727892}$ (table 2).

\section{Distance from the health facility}

\section{Overall uptake of ANC (at least one ANC visit)}

In three studies, increased distance to ANC services negatively impacted the uptake of at least one ANC visit. ${ }^{466168}$ In one study, Kenyan women who lived close to the dispensary were more likely to have at least one ANC visit, however among those women with at least one visit, the number of ANC visits increased as the distance from the dispensary increased. ${ }^{9}$ Another study also found that for each $10 \mathrm{~km}$ increase in distance from a health facility, the odds of a woman receiving different ANC services decreased by a quarter. ${ }^{93}$ In one of the studies, having a Women' Health Development Team within a $2 \mathrm{~km}$ radius from the nearest health facility increased the likelihood of at least one skilled ANC utilisation. ${ }^{86}$ Access to health services was associated with attending at least one ANC visit in another study ${ }^{48}$ (table 2 ).

\section{Frequency of ANC (at least four ANC visits)}

Women who lived a far distance from a health facility were less likely to attend four or more ANC visits in three of the studies ${ }^{345354}$ (table 2).

\section{Health insurance/user-fee exemption}

\section{Overall uptake of ANC (at least one ANC visit)}

One of the studies found that women who were insured were more likely to attend at least one ANC visit. ${ }^{94}$ In another study, the proportion of women who made at least one ANC visit during pregnancy increased significantly following user-fee exemption ${ }^{95}$ (table 2).

\section{Frequency of ANC (at least four ANC visits)}

In three studies, women who did not have health insurance were less likely to attend up to four ANC visits ${ }^{415490}$ (table 2).

\section{Timing of first antenatal visit (gestational age $<12$ weeks)}

Women who had any form of health insurance were less likely to delay the initiation of ANC. ${ }^{81}{ }^{96}$ However, another study found that women who had insurance were more likely to initiate ANC attendance in the third trimester ${ }^{72}$ (table 2).

\section{Involvement in decision-making/autonomy}

Frequency of ANC (at least four ANC visits)

Women who made decisions jointly with their husbands or partners were significantly more likely to have four or more antenatal visits compared with women whose husbands or partners made decisions alone. ${ }^{29} 3087$ Another study conducted in Eritrea and Ethiopia showed that women who were involved in major household decisions such as large purchases were more likely to use ANC at least four times ${ }^{73}$ (table 2).

\section{Timing of first antenatal visit (gestational age $<12$ weeks)}

Women who do not participate in decision-making were more likely to use ANC in the second trimester relative to the first trimester ${ }^{72}$ (table 2).

\section{Husband/partner's approval and support, social support}

Overall uptake of ANC (at least one ANC visit)

Women whose husbands have positive attitude towards ANC were more likely to use ANC than women whose husbands had negative attitude towards ANC. ${ }^{46}$

Women who had their husband/partner's approval/ permission to attend ANC were more likely to use ANC services compared with those without support from their husbands ${ }^{50} 5897$ (table 2).

\section{Frequency of ANC (at least four ANC visits)}

Women who did not experience physical intimate partner violence during the year preceding survey were more likely to have four ANC visits. ${ }^{44}$ In another study, women who had the father of their child present in their lives were more likely to use ANC services. ${ }^{98}$ Women who lacked social support were more likely to underuse ANC services compared with those with social support ${ }^{52}$ (table 2).

\section{Quality/content of ANC services}

\section{Overall uptake of ANC (at least one ANC visit)}

In one of the studies, women who received advice on ANC from health workers were more likely to attend ANC at least once in pregnancy ${ }^{97}$ (table 2).

\section{Frequency of ANC (at least four ANC visits)}

High cost of services was associated with decreased ANC use. ${ }^{53}$ In one of the studies, having an ANC at a private hospital was a predictor of delayed initiation of ANC, 
but in another, it increased the likelihood of receiving adequate ANC compared with those clients using public health facilities. ${ }^{2481}$ The level of antenatal service provision (measured as the availability of key functions, screening tests, skilled health workers and opening times) affected the quality of ANC received. Using ANC at facilities that provide a wide range of ANC services was associated with an increase in the odds of receiving the complete ANC services given in the clinic and attending ANC. ${ }^{93}$ Visits by health extension workers during pregnancy increased ANC attendance in one of the studies ${ }^{99}$ (table 2).

\section{Need factors}

Pregnancy wantedness and planning Overall uptake of ANC (at least one ANC visit)

Nine studies found that women with planned pregnancies were more likely to attend at least one ANC than those with unplanned pregnancies ${ }^{4647505558718385100}$ (table 2).

\section{Frequency of ANC (at least four ANC visits)}

Attending at least four ANC visits was positively influenced by pregnancy planning and wantedness as seen in two studies. ${ }^{4155}$ Conversely, in six studies, women with mistimed or unwanted/unplanned pregnancies were unlikely to attend at least four ANC visits ${ }^{13} 53788198100$ (table 2).

\section{Timing of first antenatal visit (gestational age $<12$ weeks)}

Women with mistimed or unwanted/unplanned pregnancies were more likely to initiate ANC in the second trimester $^{81}$ (table 2).

\section{Previous/current health and pregnancy experiences}

Overall uptake of ANC (at least one ANC visit)

Pregnancy complications, illnesses and stillbirths in previous pregnancies were found to reduce the odds of attending at least one ANC visit in two studies ${ }^{50} 55$ (table 2).

\section{Frequency of ANC (at least four ANC visits)}

Women whose pregnancy was confirmed by missed period rather than urine test were more likely to delay booking ANC visit. ${ }^{87}$ Women who attended ANC in the first trimester were more likely to attend up to four ANC visits $^{89}$ (table 2).

\section{Timing of first antenatal visit (gestational age $<12$ weeks)}

Women who had negative experiences in previous pregnancies were less likely to attend the booking ANC visit in first trimester. ${ }^{84}$ Women who had an early initiation of ANC in a previous pregnancy were more likely to book early for ANC in the subsequent pregnancy ${ }^{56}$ (table 2).

\section{DISCUSSION}

This study reviewed the predictors of ANC utilisation in SSA. Although the studies included in this review used different study designs, most were cross-sectional studies and secondary data analyses of national surveys. The determinants of ANC utilisation identified in this review include predisposing factors (such as age, education, religion, husband/partner's education, maternal occupation/employment status, husband/partner's occupation, parity), enabling factors (such as income status, place of residence, distance from the health facility, health insurance, involvement in decision-making, quality/content of ANC services) and need factors (wantedness of pregnancy, previous pregnancy experiences).

In this review, higher educational attainment for women and their husband/partner was a predisposing factor that increased overall attendance, frequency and timeliness of ANC visits in majority of the studies. These studies found that being educated increases the odds of the number and timeliness of ANC visits. This could be explained as educated women tend to be more financially independent, employed and better informed on the importance of ANC to the mother and baby. ${ }^{101}$ Similarly, studies have found that educated women and those with educated partners were more likely to use antenatal services and also initiate this within the first trimester of pregnancy. ${ }^{36} 102103$ Poor educational status has been identified as a major cause of heath inequality in ANC coverage. ${ }^{104}$ This finding highlights the need to collaborate with the educational sector to promote both female and male school enrolment and completion.

Studies in this review showed that women with a working status (employed) were found to be more likely to attend at least one and at least four ANC visits than the unemployed/not working. Being employed also increased the odds of early initiation of ANC. Employment status is closely related to income and educational status as educated women tend to be employed and consequently earn income. Beyond being a source of funds for sponsoring ANC use, employment can also increase women's exposure and access to information on ANC, thus further promoting utilisation. Women empowerment programmes and provision of employment opportunities sensitive to maternal health considerations should be encouraged in order to promote uptake of ANC services. ${ }^{105}$

As a predisposing factor, the role of high parity in reducing the odds of ANC attendance and initiation could have been because women who have had previous pregnancies may consider themselves 'experienced' and used to the routine care offered during ANC and so delay ANC initiation and number of ANC contacts made. ${ }^{106}$ Timely initiation of the first ANC visit provides a critical opportunity for health promotion, disease prevention and curative care for women and their unborn children. More efforts are needed to optimise the uptake of first ANC visit in the first trimester of pregnancy. ${ }^{107}$ Also, decreased use of ANC among high-parity women could be due to the less time available for ANC attendance due to the care of children, inadequate resources in the family and negative experiences with ANC from previous pregnancies. ${ }^{36}$

Among the predisposing factors, increasing/older maternal age increased attendance to at least one and 
four ANC visits in most of the studies that assessed its relationship with ANC utilisation. A few studies however found that younger women attended ANC clinics more than older ones. Also, younger women were more likely to attend the first ANC visit in the first trimester of pregnancy. The higher odds of early trimester booking visits in these studies may have been due to the relative childbearing inexperience (low parity) as they may be newly weds or adolescents and therefore be more likely to seek out ANC earlier than their older counterparts due to ignorance/ limited knowledge of pregnancy. Confounding effect of by parity on age may also have affected the relationship between age and ANC use as low parity was associated with early ANC booking and increased number of ANC contacts in the studies reviewed. ${ }^{15} 30404247496061707377$ Younger women have been found to initiate ANC early in a similar review. ${ }^{108}{ }^{109}$ In contrast, age was not significantly associated with the utilisation of ANC in a review of factors affecting ANC in Ethiopia. ${ }^{103}$

Most of the studies showed that being married conferred a protective effect on ANC utilisation as a predisposing factor. Married women were more likely to attend ANC and less likely to delay initiation of ANC visits when compared with their unmarried counterparts. This could be due to the psychosocial and financial support received from their husbands, planning/desirability of their pregnancy and the societal acceptability and support of their pregnant state when compared with their unmarried counterparts. ${ }^{106}$ Some studies included in this review showed that women who enjoyed support from their husbands and other social support were more likely to use ANC. This suggests and reinforces the importance of including married men in programmes that are designed to improve ANC uptake as male involvement has been proven beneficial to maternal health. ${ }^{110}$ However, one of the studies in this review found higher odds of using skilled ANC attendants among currently unmarried women. ${ }^{63}$ One possible explanation for this is that unmarried women are sole decision makers, making them empowered to seek and use ANC.

Our findings suggest that SES was one of the enabling factors reported to influence ANC utilisation across many studies as high SES increased the uptake of at least one and at least four ANC visits and the early initiation of ANC. Poverty is a known deterrent to healthcare utilisation in SSA and women of low-wealth status may be unable to afford the medical and non-medical costs associated with using ANC. ${ }^{111} 112$ Thus, because of lack of financial access, such women may not attend ANC at all, limit the number of ANC visits or even initiate ANC late in pregnancy. The effect of SES on ANC use has been documented in other studies. ${ }^{36}{ }^{113-115}$ Although free/ subsidised maternal health services are offered in some African countries, women still pay out of pocket for some direct medical costs such as laboratory investigation and non-medical costs for transport. These costs pose financial barriers to using ANC services by pregnant women. ${ }^{116} 117$ Further reflecting the role of the woman's ability to fund
ANC on utilisation, early initiation and attending ANC for at least four times were reduced in women who did not have health insurance. Women have peculiar maternal-related health needs (such as pregnancy and childbirth), thus making them use health services such as ANC, however they are oftentimes less willing and able to pay for insurance compared with men because of their low-income status and financial dependence. ${ }^{118119}$ Consequently, ANC and other maternal health services should be provided free (under mandatory social health insurance) or at subsidised rates with exemptions in order to improve the utilisation of these services and in turn reduce maternal morbidity and mortality. This review did not identify cultural/local beliefs as a determinant of ANC utilisation in contrast with findings from a similar review conducted in low and middle-income countries where women were declined from using ANC services due to fear of witchcraft attacks following blood sample collection for laboratory investigation. ${ }^{36}$ It is possible that women are getting more enlightened and as such not holding on to such beliefs.

As part of the enabling factors, rural residence negatively impacted on attendance and timing of the first ANC visit. The interplay between the peculiar characteristics of rural areas such as sparse distribution of health services and development, poor educational and employment status of residents and poor access to mass media could explain this. Similar findings on the effect of rural residence on ANC use have been documented in other studies. ${ }^{36103108}$ To improve ANC utilisation in rural areas, community-wide sensitisation on ANC, provision of basic amenities and redistribution of health services are recommended. Likewise, long travel distance between a woman's place of residence and the health facility providing ANC services was associated with a lower odds of ANC utilisation. Walking or travelling long distances could be difficult for pregnant women in addition to travel-related costs and these may discourage them from using ANC services. This negative effect of long distance on the utilisation of ANC and the continuum of maternal healthcare services has been documented in other studies. $^{120}$

Involvement in decision-making on major household decisions and ANC was one of the enabling factors that exerted a positive effect on attaining adequate and timely ANC visits. Many patriarchal communities exist in SSA in which women lack autonomy and cannot decide to seek ANC without approval from their husbands largely because of financial dependence and cultural norms. ${ }^{121}$ Autonomy and involvement of women in decision-making have been found to increase the utilisation of maternal health services. ${ }^{103} 109122$

The findings from this review suggest as part of the need factors, women whose pregnancies were planned and desired were significantly more likely to use ANC services at least once and at least four times compared with those with unplanned/undesired pregnancies. This agrees with findings from other studies. ${ }^{36}$ In order to encourage 
ANC use, more needs to be done to increase uptake of family planning by securing only desired pregnancies.

\section{Strengths and limitations}

This study involved a large number of studies that covered a wide and geographically important subregion of Africa. The review accessed several databases and used recent publications $(\leq 10$ years old). It provides evidence on the variety of determinants across different sectors affecting ANC utilisation and the importance of intersectoral collaboration in improving ANC utilisation.

The contextual differences in study settings and outcome measures used could affect the interpretation and meaning of the results. However, some determinants showed similarities and differences within and between countries. This review excluded publications in French language and this may limit the representativeness and generalisability of the findings to some settings.

\section{CONCLUSION}

Based on this review, a variety of factors affect ANC utilisation in SSA. These factors include the predisposing, enabling and need factors with the poor, uneducated, unmarried, uninsured, rural dwellers, multiparous, poorly knowledgeable, those living far from health facilities and unsupported by their husbands/partners less likely to use ANC services. These factors also demonstrate the importance of multistakeholder intersectoral collaboration in mitigating poor ANC utilisation in SSA. Thus, ministries of labour/employment, education, rural development, women affairs, finance, community and religious leaders need to collaborate with the ministry of health to achieve universal ANC coverage. Examples would include health-in-all policies, joint stakeholder policy, planning and implementation review meetings, capacity development for policymakers on intersectoral cohabitation secondments and having desk officers represent related ministries (sectors above) in the ministry of health. An example of the implementation will be the educational sector encouraging enrolment in schools while the health sector participates in curriculum development to include basic information on care in pregnancy (ANC inclusive). The ministries of works, labour and employment can lay their part by road construction to improve access to health facilities especially in rural underdeveloped areas, subsidised transport for pregnant women, provision of regular electricity to enable access to electronic media and provision of job and empowerment opportunities for women. The finance ministry can partner to provide loans, grants, conditional cash transfers and other forms of financial empowerment to women. Strengthened implementation of ANC policies with active community participation is also recommended.

Acknowledgements We acknowledge the Alliance for Health Policy and Health Systems (WHO) for providing mentorship support and funding the publication of this article under the publication mentorship programme for women in Health Policy and Health Systems (HPSR). We are grateful to John Ataguba for providing mentorship to this work. We also acknowledge the technical assistance received from the African Institute for Health Policy and Health Systems, Ebonyi State University, Abakaliki.

Contributors INO: study of conceptualisation and design, data extraction, analysis and interpretation of results, manuscript drafting and approval of the final manuscript for publication. ICA, OBE: study design, data extraction, manuscript drafting and approval of the final manuscript for publication. CJU: study design, analysis and interpretation of results, manuscript drafting and approval of the final manuscript for publication.

Funding The authors have not declared a specific grant for this research from any funding agency in the public, commercial or not-for-profit sectors.

Competing interests None declared.

Patient consent for publication Not required.

Provenance and peer review Not commissioned; externally peer reviewed.

Data availability statement All data relevant to the study are included in the article or uploaded as supplementary information.

Open access This is an open access article distributed in accordance with the Creative Commons Attribution Non Commercial (CC BY-NC 4.0) license, which permits others to distribute, remix, adapt, build upon this work non-commercially, and license their derivative works on different terms, provided the original work is properly cited, appropriate credit is given, any changes made indicated, and the use is non-commercial. See: http://creativecommons.org/licenses/by-nc/4.0/.

\section{REFERENCES}

1 White Ribbon Alliance. Respectful maternity care: the universal rights of childbearing women, 2010. Available: www. whiteribbonalliance.org/respectfulcare [Accessed 12 Aug 2017].

2 World Health Organization. Maternal mortality. Factsheets, 2018. Available: https://www.who.int/news-room/facts-sheets/detail/ maternal-mortality [Accessed 4 Nov 2018].

3 UNICEF. Maternal mortality. Matern. heal., 2017. Available: http:// data.unicef.org/topic/maternal-health/maternal-mortality [Accessed 4 Jan 2018].

$4 \mathrm{~J}$ L, Lee A, Kinney M, et al. Two million intrapartum-related still- births and neonatal deaths: where, why, and what can be done? International Journal of Gynecology \& Obstetrics 2009;107(Supplement):S5-19.

5 World Health Organization. Who recommendations on antenatal care for a positive pregnancy experience, 2016Geneva. Available: http://apps.who.int/iris/bitstream/10665/250796/1/9789241549912eng.pdf [Accessed 4 Jan 2018].

6 Carroli G, Villar J, Piaggio G, et al. Who systematic review of randomised controlled trials of routine antenatal care. The Lancet 2001;357:1565-70.

7 World Health Organization. Who antenatal care randomized trial: manual for implementation of the new model. Geneva, 2002.

8 UNICEF. Antenatal care. Matern. heal, 2017. Available: https://data. unicef.org/topic/maternal-health/antenatal-care/ [Accessed 9 Jan 2019].

9 Brown CA, Sohani SB, Khan K, et al. Antenatal care and perinatal outcomes in Kwale district, Kenya. BMC Pregnancy Childbirth 2008;8:2.

10 Nimi T, Fraga S, Costa D, et al. Prenatal care and pregnancy outcomes: a cross-sectional study in Luanda, Angola. Int $J$ Gynaecol Obstet 2016;135 Suppl 1:S72-S78.

11 Afulani PA. Determinants of stillbirths in Ghana: does quality of antenatal care matter? BMC Pregnancy Childbirth 2016;16:132.

12 Kuhnt J, Vollmer S. Antenatal care services and its implications for vital and health outcomes of children: evidence from 193 surveys in 69 low-income and middle-income countries. BMJ Open 2017;7:e017122.

13 Abel Ntambue ML, Françoise Malonga K, Dramaix-Wilmet M, Ntambue AM, Malonga FK, et al. Determinants of maternal health services utilization in urban settings of the Democratic Republic of Congo--a case study of Lubumbashi City. BMC Pregnancy Childbirth 2012;12:66.

14 Gitonga E, Muiruri F. Determinants of health facility delivery among women in Tharaka Nithi County, Kenya. Pan Afr Med J 2016;25(Suppl 2):9.

15 Dahiru T, Oche OM. Determinants of antenatal care, institutional delivery and postnatal care services utilization in Nigeria. Pan Afr Med J 2015;21.

16 De Allegri M, Ridde V, Louis VR, et al. Determinants of utilisation of maternal care services after the reduction of user fees: a case study from rural Burkina Faso. Health Policy 2011;99:210-8. 
17 Adjiwanou V, Legrand T. Does antenatal care matter in the use of skilled birth attendance in rural Africa: a multi-country analysis. Soc Sci Med 2013;86:26-34.

18 Tekelab T, Yadecha B, Melka AS. Antenatal care and women's decision making power as determinants of institutional delivery in rural area of Western Ethiopia. BMC Res Notes 2015;8:769.

19 Ataguba JE-O. A reassessment of global antenatal care coverage for improving maternal health using sub-Saharan Africa as a case study. PLoS One 2018;13:e0204822.

20 Beeckman K, Louckx F, Putman K. Determinants of the number of antenatal visits in a metropolitan region. BMC Public Health 2010;10:527.

21 Titaley CR, Dibley MJ, Roberts CL. Factors associated with underutilization of antenatal care services in Indonesia: results of Indonesia demographic and health survey 2002/2003 and 2007. BMC Public Health 2010;10:485.

22 Rai RK, Singh PK, Singh L. Utilization of maternal health care services among married adolescent women: insights from the Nigeria demographic and health survey, 2008. Womens Health Issues 2012;22:e407-14.

23 Oyewale TO, Mavundia TR. Socioeconomic factors contributing to exclusion of women from maternal health benefit in Abuja, Nigeria. Curationis 2013;38:1-11.

24 Bayou YT, Mashalla YS, Thupayagale-Tshweneagae G. The adequacy of antenatal care services among slum residents in Addis Ababa, Ethiopia. BMC Pregnancy Childbirth 2016;16:142.

25 Fagbamigbe AF, Idemudia ES. Wealth and antenatal care utilization in Nigeria : Policy implications Wealth and antenatal care utilization in Nigeria : Policy implications. Health Care for Women International 2016;38:17-37.

26 Achia TNO, Mageto LE. Individual and contextual determinants of adequate maternal health care services in Kenya. Women Health 2015;55:203-26.

27 Aseweh Abor P, Abekah-Nkrumah G, Sakyi K, et al. The socioeconomic determinants of maternal health care utilization in Ghana. Int J Soc Econ 2011;38:628-48.

28 Afulani PA. Rural/urban and socioeconomic differentials in quality of antenatal care in Ghana. PLoS One 2015;10:e0117996.

29 Ononokpono DN, Odimegwu CO, Imasiku E, et al. Contextual determinants of maternal health care service utilization in Nigeria. Women Health 2013;53:647-68.

30 Ononokpono DN, Azfredrick EC. Intimate partner violence and the utilization of maternal health care services in Nigeria. Health Care Women Int 2014;35:973-89.

31 Asundep NN, Carson AP, Turpin CA, et al. Determinants of access to antenatal care and birth outcomes in Kumasi, Ghana. J Epidemiol Glob Health 2013;3:279-88.

32 Wilunda C, Quaglio G, Putoto G, et al. Determinants of utilisation of antenatal care and skilled birth attendant at delivery in South West Shoa zone, Ethiopia: a cross sectional study. Reprod Health 2015;12:74.

33 Yaya S, Bishwajit G, Ekholuenetale M, et al. Timing and adequate attendance of antenatal care visits among women in Ethiopia. PLoS One 2017;12:e0184934.

34 Worku EB, Woldesenbet SA. Factors that Influence Teenage Antenatal Care Utilization in John Taolo Gaetsewe (JTG) District of Northern Cape Province, South Africa : Underscoring the Need for Tackling Social Determinants of Health. International Journal of MCH and AIDS 2016;5:134-45.

35 Haruna-Ogun OA. Geographical differentials in uptake of antenatal care services in Nigeria. Health Care Women Int 2018;39:34-49.

36 Simkhada B, Teijlingen ERvan, Porter M, et al. Factors affecting the utilization of antenatal care in developing countries: systematic review of the literature. J Adv Nurs 2007;61:244-60.

37 Shamseer L, Moher D, Clarke M, et al. Preferred reporting items for systematic review and meta-analysis protocols (PRISMA-P) 2015: elaboration and explanation. BMJ 2015;349:97647.

38 Wardle J, Steel A. Systematic reviews in integrative medicine: a clinician's guide to publication. Adv Integr Med 2015;2:103-9.

39 Njagi P, Arsenijevic J, Groot W. Understanding variations in catastrophic health expenditure, its underlying determinants and impoverishment in sub-Saharan African countries: a scoping review. Syst Rev 2018;7:136.

40 Akowuah JA, Agyei-Baffour P, Awunyo-Vitor D. Determinants of antenatal healthcare utilisation by pregnant women in third trimester in Peri-Urban Ghana. J Trop Med 2018;2018:1-8.

41 Sakeah E, Okawa S, Rexford Oduro A, et al. Determinants of attending antenatal care at least four times in rural Ghana: analysis of a cross-sectional survey. Glob Health Action 2017;10:1291879.
42 Mwase T, Brenner S, Mazalale J, et al. Inequities and their determinants in coverage of maternal health services in Burkina Faso. Int J Equity Health 2018;17:58.

43 Anchang-Kimbi JK, Achidi EA, Apinjoh TO, et al. Antenatal care visit attendance, intermittent preventive treatment during pregnancy (IPTp) and malaria parasitaemia at delivery. Malar J 2014;13:162.

44 Omer K, Afi NJ, Baba Moh'd Chadi, et al. Seeking evidence to support efforts to increase use of antenatal care: a crosssectional study in two states of Nigeria. BMC Pregnancy Childbirth 2014;14:380.

45 Andersen RM. Revisiting the behavioral model and access to medical care: does it matter? J Health Soc Behav 1995;36:1-10.

46 Abosse Z, Woldie M, Ololo S. Factors influencing antenatal care service utilization in hadiya zone. Ethiop J Health Sci 2010;20:75-82.

47 Regassa N. Antenatal and postnatal care service utilization in southern Ethiopia: a population-based study. Afr Health $\mathrm{Sci}$ 2011;11:390-7.

48 Assefa E, Tadesse M. Factors related to the use of antenatal care services in Ethiopia: application of the zero-inflated negative binomial model. Women Health 2017;57:804-21.

49 Saad-Haddad G, DeJong J, Terreri N, et al. Patterns and determinants of antenatal care utilization: analysis of national survey data in seven countdown countries. J Glob Health 2016;6:010404

50 Tewodros B, G/Mariam A, Dibaba Y. Factors affecting antenatal care utilization in Yem special Woreda, south-western Ethiopia. Ethiopian Journal of Health Sciences 2009;19(1:45-51.

51 Yeneneh A, Alemu K, Dadi AF, et al. Spatial distribution of antenatal care utilization and associated factors in Ethiopia: evidence from Ethiopian demographic health surveys. BMC Pregnancy Childbirth 2018;18:242.

52 Rurangirwa AA, Mogren I, Nyirazinyoye L, et al. Determinants of poor utilization of antenatal care services among recently delivered women in Rwanda; a population based study. BMC Pregnancy Childbirth 2017;17:142.

53 Gupta S, Yamada G, Mpembeni R, et al. Factors associated with four or more antenatal care visits and its decline among pregnant women in Tanzania between 1999 and 2010. PLoS One 2015;9:e101893.

54 Adewuyi EO, Auta A, Khanal V, et al. Prevalence and factors associated with underutilization of antenatal care services in Nigeria: a comparative study of rural and urban residences based on the 2013 Nigeria demographic and health survey. PLoS One 2018;13:e0197324.

55 Ayalew TW, Nigatu AM. Focused antenatal care utilization and associated factors in Debre Tabor town, Northwest Ethiopia, 2017. BMC Res Notes 2018;11:819.

56 Belayneh T, Adefris M, Andargie G. Previous early antenatal service utilization improves timely Booking: cross-sectional study at University of Gondar Hospital, Northwest Ethiopia. J Pregnancy 2014;2014:1-7

57 Kuuire VZ, Kangmennaang J, Atuoye KN, et al. Timing and utilisation of antenatal care service in Nigeria and Malawi. Glob Public Health 2017;12:711-27.

58 Birmeta K, Dibaba Y, Woldeyohannes D. Determinants of maternal health care utilization in Holeta town, central Ethiopia. BMC Health Serv Res 2013;13:256.

59 Melaku YA, Weldearegawi B, Tesfay FH, et al. Poor linkages in maternal health care services ? evidence on antenatal care and institutional delivery from a community-based longitudina study in Tigray region, Ethiopia. BMC Pregnancy and Childbirth 2014:149:418.

60 Worku AG, Yalew AW, Afework MF. Factors affecting utilization of skilled maternal care in Northwest Ethiopia: a multilevel analysis. BMC Int Health Hum Rights 2013;13:20.

61 Rossier C, Muindi K, Soura A, et al. Maternal health care utilization in Nairobi and Ouagadougou: evidence from HDSS. Glob Health Action 2014;7:24351.

62 Akinyemi JO, Afolabi RF, Awolude OA. Patterns and determinants of dropout from maternity care continuum in Nigeria. BMC Pregnancy Childbirth 2016;16:282.

63 Tarekegn SM, Lieberman LS, Giedraitis V. Determinants of maternal health service utilization in Ethiopia: analysis of the 2011 Ethiopian demographic and health survey. BMC Pregnancy Childbirth 2014;14:161.

64 Gebre E, Worku A, Bukola F. Inequities in maternal health services utilization in Ethiopia 2000-2016: magnitude, trends, and determinants. Reprod Health 2018;15:119.

65 Babalola S, Fatusi A. Determinants of use of maternal health services in Nigeria--looking beyond individual and household factors. BMC Pregnancy Childbirth 2009;9:43. 
66 Banke-Thomas A, Banke-Thomas O, Kivuvani M, et al. Maternal health services utilisation by Kenyan adolescent mothers: analysis of the demographic health survey 2014. Sexual \& Reproductive Healthcare 2017:12:37-46.

67 Verney A, Reed BA, Lumumba JB. Factors associated with socio-demographic characteristics and antenatal care and iron supplement use in Ethiopia, Kenya, and Senegal. Matern Child Nutr 2018;14:e12565.

68 Tsegay Y, Gebrehiwot T, Goicolea I, et al. Determinants of antenatal and delivery care utilization in Tigray region, Ethiopia: a crosssectional study. Int J Equity Health 2013;12:30.

69 Mbuagbaw LCE, Gofin R. A new measurement for optimal antenatal care: determinants and outcomes in Cameroon. Matern Child Health J 2011;15:1427-34.

70 Ochako R, Gichuhi W. Pregnancy wantedness, frequency and timing of antenatal care visit among women of childbearing age in Kenya. Reprod Health 2016;13:51.

71 Dansou J, Adekunle AO, Arowojolu AO. Factors associated with antenatal care services utilisation patterns amongst reproductive age women in Benin Republic: an analysis of 2011/2012 Benin Republic's demographic and health survey data. Niger Postgrad Med J 2017;24:67-74.

72 Aliyu AA, Dahiru T. Predictors of delayed antenatal care (Anc) visits in Nigeria: secondary analysis of 2013 Nigeria demographic and health survey (NdhS). Pan Afr Med J 2017;26.

73 Woldemicael G. Do Women With Higher Autonomy Seek More Maternal Health Care ? Evidence From Eritrea and Ethiopia Do Women With Higher Autonomy Seek More Maternal Health Care ? Evidence From Eritrea. Health Care for Women International 2010;31:599-620.

74 Chama-Chiliba CM, Koch SF. Utilization of focused antenatal care in Zambia: examining individual- and community-level factors using a multilevel analysis. Health Policy Plan 2015;30:78-87.

75 Ononokpono DN. Maternal health care in Nigeria: do community factors moderate the effects of individual-level education and ethnic origin? African Population Studies 2015;29:1554-69.

76 Stephenson R, Elfstrom KM. Community influences on antenatal and delivery care in Bangladesh, Egypt, and Rwanda. Public Health Rep 2012;127:96-106.

77 Yaya S, Uthman OA, Amouzou A, et al. Inequalities in maternal health care utilization in Benin: a population based cross-sectional study. BMC Pregnancy Childbirth 2018;18:194

78 Makate M, Makate C. Prenatal care utilization in Zimbabwe: examining the role of community-level factors. J Epidemiol Glob Health 2017;7:255-62.

79 Owili PO, Muga MA, Chou Y-J, et al. Family structure types and adequate utilization of antenatal care in Kenya. Fam Community Health 2016;39:188-98.

80 Doctor HV. Intergenerational differences in antenatal care and supervised deliveries in Nigeria. Health Place 2011;17:480-9. d.

81 Manzi A, Munyaneza F, Mujawase F, et al. Assessing predictors of delayed antenatal care visits in Rwanda: a secondary analysis of Rwanda demographic and health survey 2010. BMC Pregnancy Childbirth 2014:14:290.

82 Ochako R, Fotso J-C, Ikamari L, et al. Utilization of maternal health services among young women in Kenya: insights from the Kenya demographic and health survey, 2003. BMC Pregnancy Childbirth 2011;11:1.

83 Dutamo Z, Assefa N, Egata G. Maternal health care use among married women in Hossaina, Ethiopia. BMC Health Serv Res 2015;15:365.

84 Oladokun A, Oladokun RE, Morhason-Bello I, et al. Proximate predictors of early antenatal registration among Nigerian pregnant women. Ann Afr Med 2010;9:222-5.

85 Zegeye AM, Bitew BD, Koye DN. Prevalence and determinants of early antenatal care visit among pregnant women attending antenatal care in Debre Berhan health institutions, central Ethiopia. Afr J Reprod Health 2013;17:130-6.

86 Girmaye M, Berhan Y. Skilled antenatal care service utilization and its association with the characteristics of women's health development team in Yeky District, south-west Ethiopia: A multilevel analysis. Ethiop J Health Sci 2014;26:369-80.

87 Gudayu TW. Proportion and factors associated with late antenatal care Booking among pregnant mothers in Gondar town, North West Ethiopia. Afr J Reprod Health 2015;19:94-100.

88 Bobo FT, Yesuf EA, Woldie M. Inequities in utilization of reproductive and maternal health services in Ethiopia. Int $J$ Equity Health 2017;16:105.

89 Straneo M, Fogliati P, Pellis I, et al. On the way to universal coverage of maternal services in Iringa rural district in Tanzania. who is yet to be reached? Afr Health Sci 2016;16:420-8.
90 Arthur E. Wealth and antenatal care use: implications for maternal health care utilisation in Ghana. Health Econ Rev 2012;2:14.

91 Muchie KF. Quality of antenatal care services and completion of four or more antenatal care visits in Ethiopia: a finding based on a demographic and health survey. BMC Pregnancy Childbirth 2017; $17: 300$.

92 Chorongo D, Okinda FM, Kariuki EJ, et al. Factors influencing the utilization of focused antenatal care services in Malindi and Magarini sub-counties of Kilifi County, Kenya. Pan African Medical Journal 2016;25 (Suppl 2.

93 Kyei NNA, Campbell OMR, Gabrysch S. The influence of distance and level of service provision on antenatal care use in rural Zambia. PLoS One 2015;7:e46475.

94 Browne JL, Kayode GA, Arhinful D, et al. Health insurance determines antenatal, delivery and postnatal care utilisation: evidence from the Ghana demographic and health surveillance data. BMJ Open 2016;6:e008175.

95 Manthalu G, Yi D, Farrar S, et al. The effect of user fee exemption on the utilization of maternal health care at mission health facilities in Malawi. Health Policy Plan 2016;31:1184-92.

96 Kibusi SM, Sunguya BF, Kimunai E, et al. Health insurance is important in improving maternal health service utilization in Tanzania-analysis of the 2011/2012 Tanzania HIV/AIDS and malaria indicator survey. BMC Health Serv Res 2018;18:112.

97 Begum K, Ouédraogo CT, Wessells KR, et al. Prevalence of and factors associated with antenatal care seeking and adherence to recommended iron-folic acid supplementation among pregnant women in Zinder, niger. Matern Child Nutr 2018;14(Suppl):e12466.

98 Muhwava LS, Morojele N, London L. Psychosocial factors associated with early initiation and frequency of antenatal care (Anc) visits in a rural and urban setting in South Africa: a cross-sectional survey. BMC Pregnancy Childbirth 2016;16:18.

99 Afework MF, Admassu K, Mekonnen A, et al. Effect of an innovative community based health program on maternal health service utilization in North and South central Ethiopia: a community based cross sectional study. Reprod Health 2014;11:28.

100 Exavery A, Kanté AM, Hingora A, et al. How mistimed and unwanted pregnancies affect timing of antenatal care initiation in three districts in Tanzania. BMC Pregnancy Childbirth 2013;13:35

101 Grown C, Gupta GR, Pande R. Taking action to improve women's health through gender equality and women's empowerment. The Lancet 2005;365:541-3.

102 Say L, Raine R. A systematic review of inequalities in the use of maternal health care in developing countries: examining the scale of the problem and the importance of context. Bull World Health Organ 2007;85:812-9.

103 Tekelab T, Chojenta C, Smith R, et al. Factors affecting utilization of antenatal care in Ethiopia: a systematic review and meta-analysis. PLoS One 2019;14:e0214848.

104 Ayamolowo SJ, Irinoye O, Oladoyin MA. Job satisfaction and work environment of primary health care nurses in Ekiti state, Nigeria: an exploratory study. Internatinal Journal of Caring Sciences 2013;6:531-42.

105 Salihu HM, Myers J, August EM. Pregnancy in the workplace. Occup Med 2012;62:88-97.

106 Pell C, Meñaca A, Were F, et al. Factors affecting antenatal care attendance: results from qualitative studies in Ghana, Kenya and Malawi. PLoS One 2013;8:e53747.

107 Moller A-B, Petzold M, Chou D, et al. Early antenatal care visit: a systematic analysis of regional and global levels and trends of coverage from 1990 to 2013. Lancet Glob Health 2017;5:e977-83

108 Hajizadeh S, Tehrani FR, Simbar M, et al. Factors Influencing the Use of Prenatal Care : A Systematic Review. Journal of Midwifery and Reproductive Health 2016;4:544-57.

109 Tesfaye G, Loxton D, Chojenta C, et al. Delayed initiation of antenatal care and associated factors in Ethiopia: a systematic review and meta-analysis. Reprod Health 2017;14:150.

110 Yargawa J, Leonardi-Bee J. Male involvement and maternal health outcomes: systematic review and meta-analysis. J Epidemiol Community Health 2015;69:604-12.

111 Peters DH, Garg A, Bloom G, et al. Poverty and access to health care in developing countries. Ann N Y Acad Sci 2008;1136:161-71.

112 Houweling TAJ, Ronsmans C, Campbell OMR, et al. Huge poor-rich inequalities in maternity care: an international comparative study of maternity and child care in developing countries. Bull World Health Organ 2007;85:745-54.

113 Carvajal-Aguirre L, Amouzou A, Mehra V, et al. Gap between contact and content in maternal and newborn care : An analysis of data from 20 countries in sub-Saharan Africa. Journal of Global Health 2017;7:1-8. 
114 Ayanore MA, Pavlova M, Groot W. Unmet reproductive health needs among women in some West African countries: a systematic review of outcome measures and determinants. Reprod Health 2015;13:5.

115 Goli S, Nawal D, Rammohan A, et al. Decomposing the socioeconomic inequality in utilization of maternal health care services in selected countries of South Asia and sub-Saharan Africa. J Biosoc Sci 2018;50:749-69.

116 Kalu-Umeh NN, Sambo MN, Idris SH, et al. Costs and patterns of financing maternal health care services in rural communities in northern Nigeria: evidence for designing national fee exemption policy. Int J MCH AIDS 2013;2:163-72.

117 Dalinjong PA, Wang AY, Homer CSE. Has the free maternal health policy eliminated out of pocket payments for maternal health services? views of women, health providers and insurance managers in northern Ghana. PLoS One 2018;13:e0184830.
118 Ataguba JE, Ichoku HE, Fonta WM. Estimating the willingness to pay for community healthcare insurance in rural Nigeria. available at SSRN 1266163, 2008.

119 Adebayo EF, Uthman OA, Wiysonge CS, et al. A systematic review of factors that affect uptake of community-based health insurance in low-income and middle-income countries. BMC Health Serv Res 2015;15:543.

120 Kawakatsu Y, Sugishita T, Oruenjo K, et al. Determinants of health facility utilization for childbirth in rural Western Kenya: crosssectional study. BMC Pregnancy Childbirth 2014;14:265

121 Downe S, Finlayson K, Tunçalp Özge, et al. Provision and uptake of routine antenatal services: a qualitative evidence synthesis. Cochrane Database of Systematic Reviews 2019;46. Art No: CD012392.

122 Story WT, Burgard SA. Couples' reports of household decisionmaking and the utilization of maternal health services in Bangladesh. Soc Sci Med 2012;75:2403-11. 